\title{
A case of tick-borne relapsing fever in pregnancy
}

\author{
John C Lam ${ }^{1 *}$, Oscar E Larios ${ }^{1,2}$, Michael D Parkins ${ }^{1,3}$, Stephen D Vaughan ${ }^{1}$
}

\begin{abstract}
Tick-borne relapsing fever (TBRF) is an infection caused by Borrelia spirochetes. In North America, Borrelia hermsii is the most common cause for TBRF. This vector-borne disease is transmitted by Ornithodoros hermsi, a soft-bodied tick found in high altitudes in northwestern United States and southwestern Canada. Once bitten by the tick and infected by B. hermsii, episodes of fever alternating with afebrile periods can occur.
\end{abstract}

A case of TBRF in a pregnant host was complicated by Jarisch-Herxheimer reaction requiring critical care. This case emphasizes the importance of maintaining a high index of suspicion in TBRF. Clinician recognition, diagnosis and treatment of TBRF as well as public awareness of strategies to prevent tick bites should be strengthened.

Suggested citation: Lam JC, Larios OE, Parkins MD, Vaughan SD. A case of tick-borne relapsing fever in pregnancy. Can Commun Dis Rep 2020;46(10):362-4. https://doi.org/10.14745/ccdr.v46i10a09

Keywords: tick-borne relapsing fever, Borrelia hermsii, Ornithodoros, Jarisch-Herxheimer reaction, disease surveillance

\section{Introduction}

Tick-borne relapsing fever (TBRF) can be challenging to diagnose because of difficulties in isolating the causative bacterium, Borrelia hermsii, in the laboratory. Furthermore, clinicians may not consider TBRF in the differential diagnosis of febrile illnesses as the vector is often unrecognized. In addition, TBRF is a non-reportable illness.

Here, we report a life-threatening case of TBRF in a pregnant individual, discuss some treatment aspects and advocate for active case surveillance by public health officials in areas of high risk.

Written informed consent was obtained from the patient to publish this case report and the accompanying images.

\section{Case}

A 30-year-old previously healthy primagravida woman, at 17 weeks' gestation, presented to hospital in Calgary, Alberta, with a four-day history of fevers, chills and multiple episodes of emesis. Prior to symptom onset, she had spent five days in the Okanagan region of British Columbia on a summer family hiking trip. The entire family stayed in a well-kept air-conditioned house in Vernon, British Columbia, that her extended family regularly inhabited. There was no history of rodent inhabitation or pest control concerns in or around the house.
The patient had had an unremarkable prenatal course, with negative screening serology for syphilis and HIV. There was no exposure history consistent with rat bite fever, leptospirosis or louse-borne relapsing fever. She reported multiple unknown insect bites across her torso, but no rash, during her holiday. On presentation, she was febrile (temperature $38.9^{\circ} \mathrm{C}$ ), hypotensive (blood pressure 85/52) and tachycardic (heart rate 128 beats/minute). The remainder of her examination was otherwise non-contributory.

Initial investigations identified pancytopenia with hemoglobin of $78 \mathrm{~g} / \mathrm{L}$, platelets of $27 \times 10^{9} / \mathrm{L}$ and white blood cells of $3.4 \times 10^{9} / \mathrm{L}$ and with lymphopenia at $0.1 \times 10^{9} / \mathrm{L}$. Metabolic acidosis with $\mathrm{pH}$ of 7.21 and lactate of $4.3 \mathrm{mmol} / \mathrm{L}$ were also identified. A peripheral blood smear found the presence of spirochetes and a presumptive diagnosis of TBRF was made (Figure 1).

Treatment with penicillin $\mathrm{G}$ at four million units intravenously every four hours was commenced. Two hours after penicillin initiation, the patient developed chills and worsened hypotension (blood pressure 70/50) despite administration of $6 \mathrm{~L}$ of crystalloid resuscitation. This is characteristic of a Jarisch-Herxheimer reaction. The patient was subsequently transferred to the intensive care unit for closer monitoring. Her hypotension resolved within one day, and pancytopenia improved within the week. She was discharged to complete a 14-day course 


\section{Figure 1: Wright-Giemsa stained peripheral blood smear showing spirochetes}

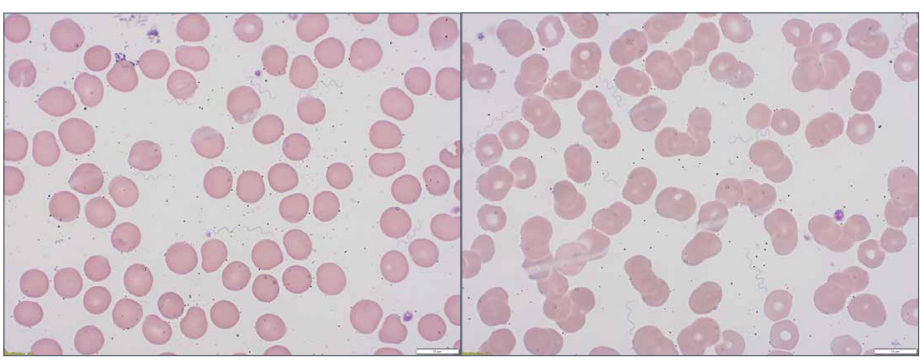

of intravenous penicillin G. Molecular testing of blood by $16 \mathrm{~S}$ ribosomal polymerase chain reaction confirmed $B$. hermsii as the causative pathogen.

At 40 weeks, the patient delivered a healthy infant.

\section{Discussion}

B. hermsii is a spirochete implicated in TBRF. B. hermsii commonly occurs in mountainous regions of North, Central and South America. In Canada, approximately 50 cases have been reported over the last two decades (1). TBRF is transmitted via the night-biting soft tick Ornithodoros hermsi (2). O. hermsi are found in southern British Columbia and northwestern United States, preferring coniferous forests at 450-2,450 m occupied by rodents such as tree squirrels and chipmunks (3). O. hermsi live in the nests of rodent reservoirs and feed nocturnally. In the absence of rodents, $\mathrm{O}$. hermsi will feed on humans.

Infected individuals present with characteristic recurrent three-day fevers punctuated by week-long periods of being afebrile. Episodes of fevers and tachycardia, known as the "chill phase," are followed by the "flush phase," during which transient hypotension and drenching sweats occur. The acuity of the patient's presentation is likely linked to the relative immunosuppression of pregnancy, based on reports of increased severity in pregnant patients (4). The potential for poor neonatal outcomes is well documented (5).

Microscopy may be useful in diagnosing TBRF because the spirochetes associated with $B$. hermsii are clearly visible, particularly during febrile episodes. Peripheral blood smears stained with Wright-Giemsa stain are positive for the presence of extracellular spirochetes in about $70 \%$ of patients, particularly during the flush phase (6). Although molecular testing can be used to confirm spirochete species, testing turnaround time is lengthy, and it is not appropriate to wait for results prior to initiating therapy. Similarly, serological testing performed weeks after infection confirms presence of appropriate antibody response but is of little use in the acute management of the illness.
TBRF during pregnancy is rare, and considerations of drug therapy and neonatal consequences are important. Oral doxycycline or intravenous beta-lactams are suitable therapies, but intravenous beta-lactams are preferable in pregnancy because of the teratogenicity of tetracyclines (7). Jarisch-Herxheimer reaction, characterized by chills, fevers and hypotension, can develop within 24 hours in patients treated for spirochetal infections. Jarisch-Herxheimer reaction has been documented in upwards of $50 \%$ of patients treated for $\operatorname{TBRF}(8,9)$. Thrombocytopenia associated with acute TBRF poses risks of preterm labour and spontaneous abortion. Cases of placental transmission to the neonate have also been reported (4).

Because TBRF is not a reportable disease in Canada, it is not known whether distribution of $B$. hermsii and incidence of TBRF is similar to a decade ago. Over $80 \%$ of patients will not develop a rash from a nighttime painless bite or exhibit the characteristic fever syndrome. As such, the burden of TBRF in southwestern Canada is likely underestimated (10). Case surveillance and reporting may improve systemized approach to diagnosis and greater clinician awareness of this disease.

Although rare, TBRF can have severe sequelae and be fatal (11). Enhanced public awareness for TBRF may lead to a more concerted effort to prevent TBRF by reducing rodent habitats, contacting pest control for chemical treatment of rodent-infested areas and educating people to apply topical repellants (e.g. permethrin) when sleeping (12). Active case surveillance could be considered by public health officials in areas of high risk.

Geographic distribution of $O$. hermsi may expand in Canada with predicted changes in climate (13).

\section{Conclusion}

This case illustrates TBRF as a life-threatening complication of pregnancy in the absence of the typical exposure in a rustic dwelling.

Surveillance data would be useful for characterizing the epidemiology of this probable underdiagnosed infection in Canada.

\section{Authors' statement}

All authors were involved in the management of the patient. JCL wrote the initial draft of the manuscript and all authors contributed to its revision. SDV oversaw manuscript preparation and revisions. All authors read and approved the final manuscript. 
A copy of the written consent is available for review by the Editor-in-Chief of Canada Communicable Disease Report.

\section{Competing interests}

None.

The case was presented in part at the Clinical Grand Rounds, European Congress of Clinical Microbiology \& Infectious

Diseases 2019, Amsterdam Noord, the Netherlands.

\section{Funding}

This research did not receive any specific grant from funding agencies in the public, commercial or not-for-profit sectors.

\section{References}

1. Hussein $\mathrm{H}$, Showler $\mathrm{A}$, Tan $\mathrm{DH}$. Tick-borne relapsing fever in pregnancy. CMAJ 2014 Feb;186(2):131-4. DOI PubMed

2. Morshed M, Drews SJ, Lee MK, Fernando K, Man S, Mak S, Simpson Y, Wong Q, Patrick DM. Tick-borne relapsing fever in British Columbia: a 10-year review (2006-2015). BC Med J 2017;59(8):412-7. https://bcmj.org/articles/ tick-borne-relapsing-fever-british-columbia-10-year-review2006\%E2\%80\%932015

3. Dworkin MS, Schwan TG, Anderson DE Jr. Tick-borne relapsing fever in North America. Med Clin North Am 2002 Mar;86(2):417-33. DOI PubMed

4. Centers for Disease Control and Prevention (CDC). Tickborne relapsing fever in a mother and newborn child--Colorado, 2011. MMWR Morb Mortal Wkly Rep 2012 Mar;61(10):174-6. PubMed
5. Jongen $\mathrm{VH}$, van Roosmalen J, Tiems J, Van Holten J, Wetsteyn JC. Tick-borne relapsing fever and pregnancy outcome in rural Tanzania. Acta Obstet Gynecol Scand 1997 Oct;76(9):834-8. DOI PubMed

6. Parola P, Raoult D. Ticks and tickborne bacterial diseases in humans: an emerging infectious threat. Clin Infect Dis 2001 Mar;32(6):897-928. DOI PubMed

7. Nahum GG, Uhl K, Kennedy DL. Antibiotic use in pregnancy and lactation: what is and is not known about teratogenic and toxic risks. Obstet Gynecol 2006 May;107(5):1120-38. DOl PubMed

8. Dworkin MS, Anderson DE Jr, Schwan TG, Shoemaker PC Banerjee SN, Kassen BO, Burgdorfer W. Tick-borne relapsing fever in the northwestern United States and southwestern Canada. Clin Infect Dis 1998 Jan;26(1):122-31. DOI PubMed

9. Butler T. The Jarisch-Herxheimer reaction after antibiotic treatment of spirochetal infections: a review of recent cases and our understanding of pathogenesis. Am J Trop Med Hyg 2017 Jan;96(1):46-52. DOI PubMed

10. Dworkin MS, Schwan TG, Anderson DE Jr, Borchardt SM. Tick-borne relapsing fever. Infect Dis Clin North Am 2008 Sep;22(3):449-68. DOI PubMed

11. Goubau PF. Relapsing fevers. A review. Ann Soc Belg Med Trop 1984;64(4):335-64. PubMed

12. Juckett G. Arthropod-borne diseases: the camper's uninvited guests. Microbiol Spectr 2015 Aug;3(4):1-12. DOI PubMed

13. $K M$, Johnson TL, Teglas MB, Nieto NC, Schwan TG. Ecological niche modeling and distribution of Ornithodoros hermsi associated with tick-borne relapsing fever in western North America. PLoS Negl Trop Dis 2017 Oct;11(10):e0006047. DOI PubMed 